\title{
COMMUNICATIONS
}

\section{PATHOLOGICAL EXAMINATION OF A HUMAN EYE CONTAINING AN ANTERIOR CHAMBER ACRYLIC IMPLANT}

\author{
BY
}

\author{
N. ASHTON AND D. P. CHOYCE
}

\author{
Department of Pathology, Institute of Ophthalmology, University of London, and Southend General \\ Hospital, Essex
}

ACRYLIC lenses were first inserted into human eyes by Harold Ridley in 1950 to correct the visual defect in cases of aphakia, and the lens was implanted behind the iris in front of an intact posterior lens capsule at the time of the extracapsular extraction. The Ridley operation has since been repeated some hundreds of times and clinical reports have been published in many different countries, but there are only four contributions, representing examinations of eleven eyes, on the pathology of human eyes containing acrylic lenses. Redmond Smith (1956) described nine of these, Theobald (1953) had previously reported on one of the cases in Redmond Smith's series, and Rintelen and Saubermann (1956) and François, Rabaey, and Evens (1956) each described a single eye. In every case there was an inflammatory reaction of varying intensity, which Theobald (1953) and François and others (1956) attributed to the acrylic material itself, whereas Redmond Smith, who found no relationship between the extent of the fibrous reaction and the time the lens had remained in the eye, would rather incriminate the Cetrimide antiseptic in which the acrylic was sterilized. In no case was there any evidence of a sympathetic uveitis.

In an attempt to overcome some of the disadvantages of the Ridley operation, the anterior chamber implant was devised by Strampelli (1953, 1954) and later by Schreck (1955) and Scharf (1955). Various patterns of lens have been designed, including a recent one by Ridley (1957), but they all have a refracting surface centred over the pupil while the extremities rest in the angles of the anterior chamber to act as supports. Theoretically the lens should not be in contact with the corneal endothelium or with the main body of the iris.

Although it has been shown that acrylic lenses are well tolerated in the anterior chambers of rabbits (Fedrizzi, 1955, and Poli and Romagnoli, 1955) the findings of King and Skeehan (1957), who introduced acrylic lenticuli into the anterior chamber of two monkeys and three cats, are less reassuring. Severe iritis occurred clinically in only one animal, but all showed histological evidence of mild iritis and cyclitis. It would therefore seem of particular 
interest to know what pathological changes may be found in a human eye containing an anterior chamber implant, and to compare them with those reported in the Ridley operation. The following account is the first such report in the literature.

\section{Case Report}

A man aged 73 was first seen in 1956 complaining of poor sight in the left eye. The visual acuity was perception of light only with accurate projection, and there was a mature senile cataract. The right eye was healthy in all respects with $6 / 6$ visual acuity. In March, 1957, the cataract was extracted by a simple extra-capsular operation and recovery and convalescence were uneventful; 6 weeks later the visual acuity was $6 / 6$ with a 12 D.sph.

The patient was considered to be a suitable subject for an anterior chamber implant and in June, 1957, a 13-mm. Strampelli type implant (sterilized in Cetavlon) was inserted horizontally, twin peripheral iridectomies being performed at 2 and 4 o'clock. The incision was made from 5 to 1 o'clock, with a von Graefe's knife, $1 \mathrm{~mm}$. on the corneal side of the limbus; its upper half overlapped the previous cataract incision and was $1 \mathrm{~mm}$. anterior to it. One suture was used to close the corneal incision; 3 days later this was removed and at the same time a routine subconjunctival injection of $10 \mathrm{mg}$. cortisone acetate was given. On the fifth post-operative day the patient was discharged from hospital and instructed to apply 1 per cent. oculentum cortisone to the lower fornix once daily.

The eye was almost white 6 weeks after the insertion of the implant and the unaided visual acuity was 6/24. Most patients with this standard of vision at this stage achieve a final acuity of $6 / 6$ or better, sometimes with a small cylindrical correction (Choyce, 1958). However, despite this satisfactory progress, 2 days after his last attendance at the outpatient's clinic he committed suicide. His wife, who found him dead at the bottom of their garden with his throat cut, said that he had not been able to sleep, had felt his memory going, and was afraid of losing his sanity. His suicide was unconnected with the eye operation.

Permission was given for the eye to be removed and this was done 6 hours after death.

\section{Pathological Examination}

Macroscopical Examination.-The left eye showed a limbal operation wound at 12 o'clock, and a diagonally-placed acrylic implant in the anterior chamber lying with its long axis passing from the nasal side at 8 o'clock to the temporal side at 2 o'clock. The globe was opened obliquely along this axis in order to show the implant in situ; it appeared to be fitting closely into the angles with no obvious inflammatory reaction. At no point anteriorly was it in contact with the corneal endothelium and posteriorly it arched away from the main body of the iris. Two peripheral iridectomies could be seen, one being occluded by a plaque of lens material behind the iris. The remainder of the eye appeared normal. The acrylic implant was then removed and celloidin sections of the eye prepared.

Microscopical Examination.-A chronic inflammatory reaction was present at the limbus and three healed perforating wounds passed obliquely through 
the periphery of the cornea, two on the temporal side of the cornea and one on the nasal side; at the inner aspect of one of these wounds the cornea was denuded of Descemet's membrane and covered only by endothelium (Figs 1 and 2).

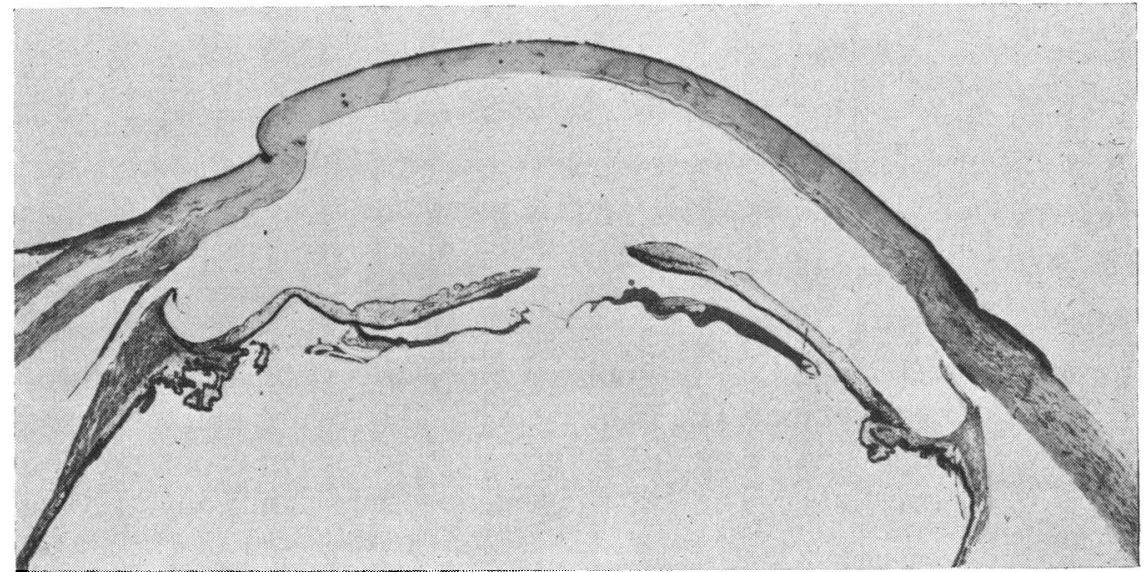

Fig. 1.-Anterior segment, showing corneo-iridic angles distorted to form cups of atrophic tissue extending outwards and backwards into the ciliary body. Lens remnants are seen behind the iris. Haematoxylin and eosin. $\times 7 \cdot 5$.

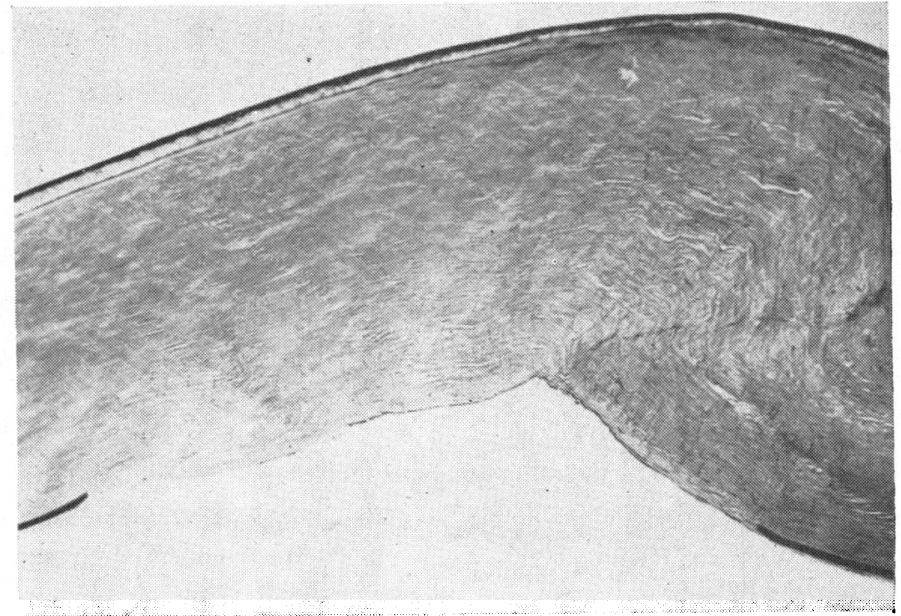

FIG. 2.-Cornea, showing absence of Descemet's membrane on inner aspect of a healed operation wound (cf. Fig. 4). Periodic acid-Schiff stain. $\times \mathbf{4 8}$

Schlemm's canal and the uveoscleral meshwork appeared perfectly healthy; the filtration angles were widely patent, and on both sides the root of the iris had been pushed backwards and lay adjacent and adherent to the ciliary body. On both sides the implant had considerably distorted the tissues of the corneo-iridic angles to form cups of compressed atrophic tissue 
extending outwards and backwards into the ciliary body (Fig. 1). Within this boundary tissue there was a very mild chronic inflammatory infiltration consisting of lymphocytes, plasma cells, a few plasmacytoid cells, and a delicate fibrous reaction. No eosinophils or giant cells could be seen. On the temporal side a folded strip of Descemet's membrane lay buried in the tissues of the iris root. On both sides the ciliary muscle was stretched and atrophic in the angle region and had broken away from the attachments at the scleral spur. Although this must have been due to artefact occurring during the processing of the specimen, it is an unusual finding with our technique and would appear to indicate an undue weakness of, or tension within, the muscle at these points (Figs 3, 4, and 5, opposite).

Posterior synechiae to the ring remnants of the cataractous lens were present and in some sections lens material could be seen astride and posterior to an iridectomy wound. A few inflammatory cells were scattered throughout the anterior vitreous. The macular region showed a marked degree of oedema with cystic spaces containing fibrinous exudate in the outer molecular layer (Fig. 6, overleaf). The eye showed no other significant histological abnormality.

\section{Discussion}

The presence of a large foreign body of this nature in the anterior chamber raises a number of questions as to its possible influence on the eye, and the more important of these will now be considered in relation to our findings.

(1) Damage to Corneal Endothelium.-Sections of the cornea in this case show clearly that trauma occurring at the time of operation is not inconsiderable. A portion of Descemet's membrane was detached from the posterior surface of the cornea and found buried in the tissue of the angle of the anterior chamber. Clearly if this trauma is excessive a severe endothelial dystrophy could be precipitated; the surgical technique should, therefore, be as gentle as possible. Only the finest corneal forceps, needles, and suture material should be used, and only one suture should be inserted. A preexisting endothelial dystrophy would almost certainly be aggravated by an acrylic implant and would be a contraindication to the operation. With regard to endothelial injury occurring after the operation, the sections showed that the implant was nowhere in direct contact with the endothelium, and there would therefore seem to be no reason why a dystrophy should occur if the implant has been properly inserted. Nevertheless, patients should be warned to be careful, as when washing the face, that they do not press unduly on the eyes as this might bring the endothelium in contact with the acrylic implant, and in time cause an endothelial dystrophy. This is unlikely to occur, however, since measurement of the maximum clearance between the posterior surface of the cornea and the anterior surface of the implant (as estimated in vivo with the special measuring device fitted to the Zeiss Opton corneal microscope) discloses an average of 1.5 to $2 \mathrm{~mm}$. 


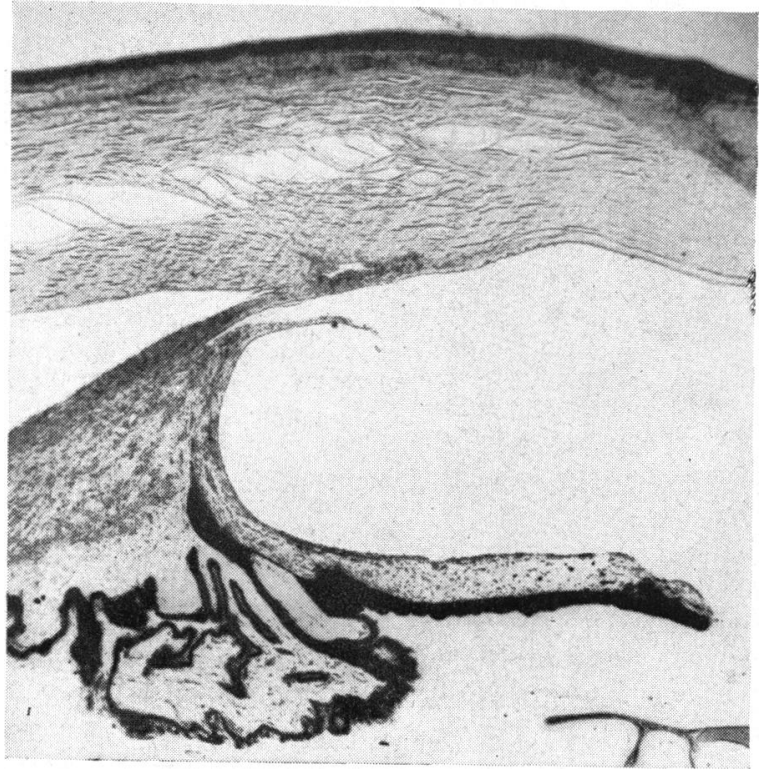

Fig. 3.-Distorted angle, showing backward displacement of iris and ciliary body which are adherent to each other. Splitting and detachment of the ciliary muscle may be due to artefact. The structures in this region are atrophic. Haematoxylin and eosin. $\times 32$.

Fig. 4.-High-power view of angle on temporal side, showing a strip of Descemet's membrane buried in the tissues of the iris root (cf. Fig. 2). Periodic acidSchiff and haematoxylin. $\times 72$.
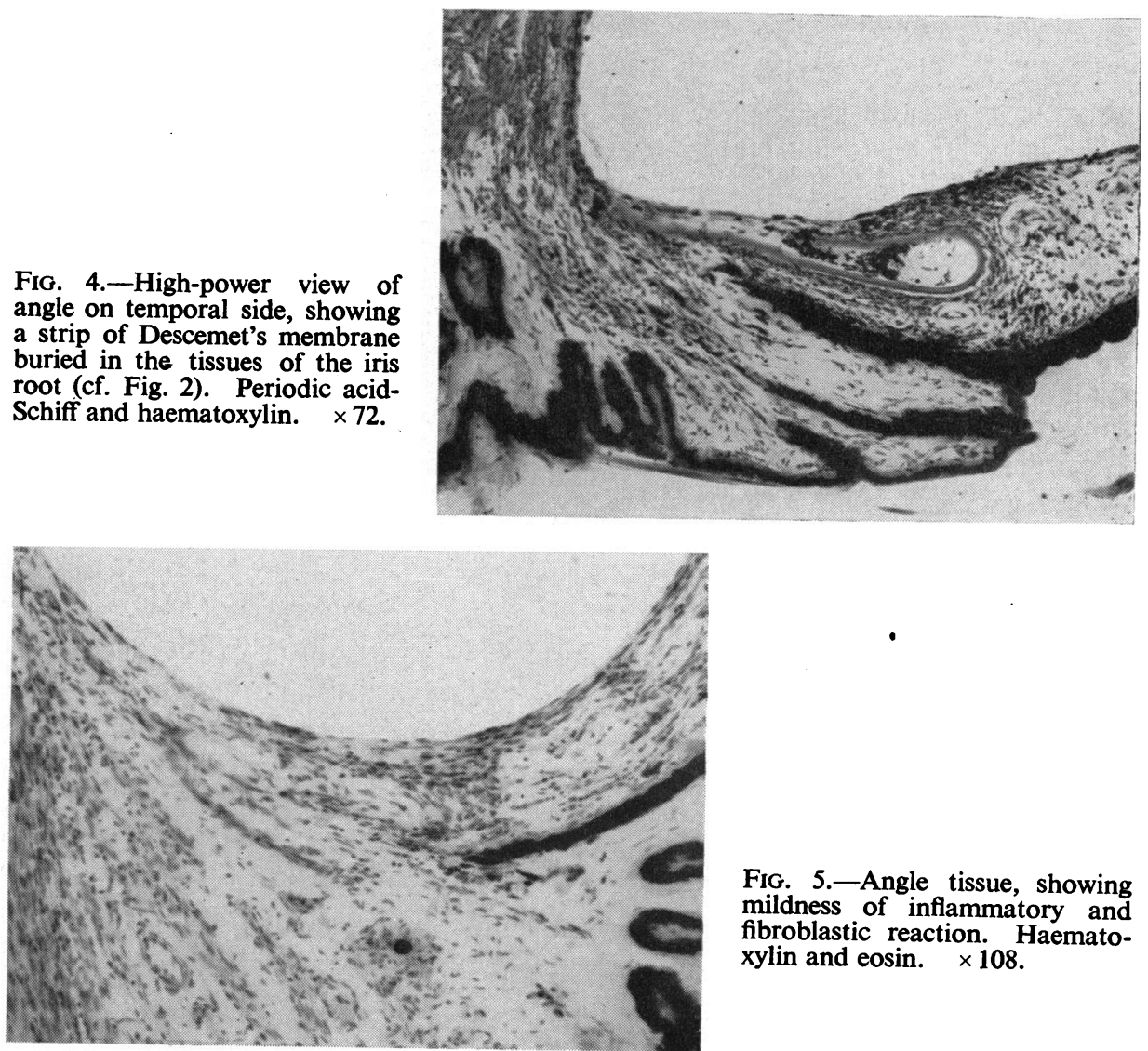

Fig. 5.-Angle tissue, showing mildness of inflammatory and fibroblastic reaction. Haematoxylin and eosin. $\times 108$. 


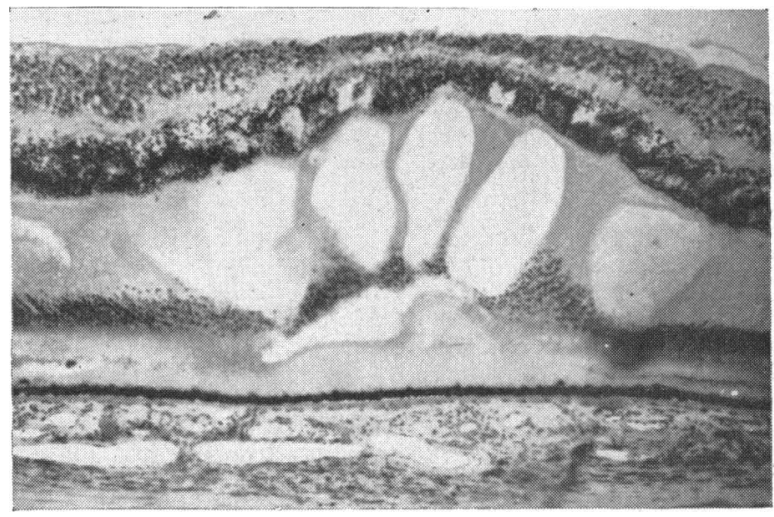

Fig. 6.-Macular region, showing marked oedema with cyst formation. Haematoxylin and eosin. $\times 55$.

(2) Mechanical Displacement of the Implant.-Sections of the angle show clearly that the iris root is distorted and atrophic, while the anterior attachment of the ciliary muscle appears attenuated and weakened, and we therefore consider it possible that after slight trauma a fracture of the iris root may take place, leading to a posterior dislocation of the foot of the implant or, alternatively, a localized cyclodialysis may occur, with displacement of the implant towards the supra-choroidal space. It is to be remembered that the atrophy in this case had taken only 6 weeks to develop, so that the above complications might have become even more serious hazards as time went on. On the other hand, both Choyce (1958) and Ferguson (1958) have reported cases in which eyes containing anterior chamber implants were subjected to further trauma at a later date. In Choyce's case, a boy was hit in the affected eye 16 months after the insertion of the implant; once the hyphaema had absorbed it was noticed that the implant had rotated about $60^{\circ}$ round an antero-posterior axis, like the blade of a propeller. Ferguson's patient was struck in the eye by a fist. In neither of these cases was the implant luxated posteriorly. Clearly this stretching and atrophy of the structures of the angle might be lessened if the thickness of the haptic portion of the implant could be reduced, and the manufacturers of these implants (Rayners Optical Company) have already been requested to reduce the thickness from 0.91 to $0.5 \mathrm{~mm}$.

(3) Inflammatory Sequelae.-The inflammatory reaction in the eye under consideration was surprisingly mild and was practically confined to the iris root in contact with the acrylic implant, but even here there were no eosinophils or giant cells as in the cases reported by Redmond Smith (1956). Nor was there a fibrous reaction of the intensity seen with the Ridley implant. It has to be remembered, of course, that the cortisone ointment probably subdued inflammatory reactivity to some extent, and this mild inflammatory picture may therefore be misleading. In fact, according to Forgas (1957), iridocyclitis and hypertension have already been encountered in these cases. 
Glaucoma secondary to anterior uveitis would therefore appear to be a possible complication, but there is little reason to suppose that sympathetic ophthalmitis could occur.

(4) Obstruction to Aqueous Outflow.-No evidence was found that glaucoma may be expected from angle blockage through direct occlusion by the implant, nor from progressive fibrosis of the uveo-scleral meshwork through its irritant action, although the implant had hardly been in situ long enough to exclude the latter possibility.

(5) Macular Oedema.-The marked degree of macular oedema found in this case was unexpected; this is a well-recognized complication of cataract extraction and may have been a chance occurrence in this case, precipitated perhaps by hypotony after two successive operations in an elderly patient (Grignolo, 1952; Dellaporta, 1955; Nicholls, 1956; Maumenee, 1957; Welch and Cooper, 1958). While there is no evidence to relate macular oedema to the lens implant per se, it would be of interest to follow other cases with this complication in mind.

\section{Summary}

The first histopathological examination of a human eye containing an anterior chamber implant is reported.

The chief findings were injury to Descemet's membrane, distortion of the corneo-iridic angles with atrophy of the adjacent ciliary muscle, a mild inflammatory reaction in the angle tissues in contact with the implant, and a marked degree of macular oedema. There was no evidence of a "foreign body" or sympathetic type of reaction.

These findings are compared with histopathological reports on eyes subjected to the Ridley operation, and are evaluated with regard to the possible sequelae of the anterior chamber operation.

\section{REFERENCES}

CHOYCE, D. P. (1958). Trans. ophthal. Soc. U.K., 78, 459.

Dellaporta, A. (1955). Amer. J. Ophthal., 40, 781.

Fedrizzi, G. (1955). Atti Soc. oftal. Lombarda, 10, 339.

Ferguson, W. J. W. (1958). Trans. ophthal. Soc. U.K., 78, 467.

Forgas, A. A. (1957). Thesis, Fac. Med. Barcelona, pp. 27.

François, J., Rabaey, M., and Evens, L. (1956). Ann. Oculist. (Paris), 189, 923.

Grignolo, A. (1952). A.M.A. Arch. Ophthal., 47, 760.

KING, J. H., Jr., and SkeEHAN, R. A. Jr. (1957). Ibid., 58, 392.

Maumenee, A. E. (1957). Trans. Amer. Acad. Ophthal. Otolaryng., 61, 51.

Nicholls, J. V. V. (1956). A.M.A. Arch. Ophthal., 55, 595.

Poli, A. de, and Romagnoli, M.A. (1955). Atti Soc. oftal. Lombarda, 10, 143.

RIDLEY, H. (1957). Brit.J. Ophthal., 41, 355.

Rintelen, F., and SaubermanN, G. (1956). Ophthalmologica (Basel), 131, 369.

SCHARF, J. (1955). Ber. dtsch. ophthal. Ges., 59, 222.

SCHRECK, E. (1955). Ibid., 59, 212.

SMith, Redmond (1956). Brit. J. Ophthal., 40, 473.

STrampelli, B. (1953). Atti Soc. oftal. Lombarda, 8, 292. (1954). Ann. Ottal., 80, 75.

Theobald, G. D. (1953). Amer. J. Ophthal., 36, 1471.

Welch, R. B., and CoOper, J. C. (1958). A.M.A. Arch. Ophthal., 59, 665. 